\title{
An analysis of the impact of a leadership intervention on an undergraduate work-based learning project for human resource management students
}

\author{
Trevor Gerhardt \\ WBL Department, GSM London Ltd, London, UK
}

\begin{abstract}
Purpose - The purpose of this paper is to analyse the impact of an action research intervention during a work-based learning (WBL) project among human resource management (HRM) students at a business college in London. The intervention was the researcher's meeting with the nominated group leaders to facilitate reflection on their leadership and instil confidence.

Design/methodology/approach - This paper is based on an action research leadership intervention on a broader undergraduate WBL module taught across nine disciplines and numerous projects. The action learning involved the phases of action, reflection, learning and planning. The sample was five group leaders on one of the projects for HRM students. A content analysis of their assessment submissions was included in the reflection, learning and planning phases.

Findings - Based on a content analysis, most of the group leaders acknowledged the leadership intervention in their submissions in varying degrees of quantity and quality. The findings reflect the impact of the intervention upon leadership confidence and the application of theory on practice. Specific leadership input would enhance the impact. The intervention did address confidence which impacted self-directed learning.

Research limitations/implications - The research is limited to a specific context and small sample. It is limited by the fact that reflective assessment work could not be used in comparison with the project assessment submissions.

Practical implications - The research demonstrates directly from the assessed submissions of students the benefit of WBL with a specific focus on confidence, leadership, reflection and self-directed learning. It demonstrates as an example the application of action research on a small WBL sample.

Social implications - The research is the evidence of the importance of leadership and confidence among mature adults in WBL contexts.

Originality/value - This paper demonstrates the impact of WBL on the learning of mature adults and, furthermore, the impact of a leadership intervention on the motivation of students for self-directed learning.

Keywords Leadership, Reflection, Work-based learning, Action research, Self-directed learning

Paper type Research paper

\section{Introduction}

Boud and Solomon (cited in Lemanski and Overton, 2016, p. 278) define work-based learning (WBL) as "a partnership between universities and employers to deliver learning that meets the needs of the learners, contributes to the long-term development of their employer and results in an accredited qualification". It was originally conceived as most appropriate for a mature person already established at work (Garnett, 2016). The researcher is the Project Lead of such undergraduate (UG)-taught WBL programmes at the Greenwich School of Management in London (GSM London). WBL is a structured programme of learning where

(C) Trevor Gerhardt. Published in Journal of Work-Applied Management. Published by Emerald Publishing Limited. This article is published under the Creative Commons Attribution (CC BY 4.0) licence. Anyone may reproduce, distribute, translate and create derivative works of this article (for both commercial and non-commercial purposes), subject to full attribution to the original publication and authors. The full terms of this licence may be seen at http://creativecommons.org/licences/by/4.0/legalcode
\end{abstract}

Impact of a leadership intervention

Received 15 September 2018 Revised 2 November 2018 Accepted 7 December 2018 
JWAM

11,1

work skills are practiced or experienced (Allan, 2015). WBL questions the more traditional notion that knowledge is held and transferred by the privileged few through formal situations in pre-determined ways (Helyer, 2016). Instead, WBL, specifically, enables accelerated access through transferable skills, initial professional preparation for the "real world", explicit contextual professional development and the use of problem-based learning (Allan, 2015). WBL increases employability, transferable skills and learning that is based upon applying theory in practice (Toledano-O'Farrill, 2017). Allan (2015), however, does warn that there is much ambiguity and cross-conceptualisation taking place in the literature between WBL, work-related learning (WRL) and workplace learning (WPL). As such, apprenticeships in the United Kingdom (UK), it can be argued, have been rediscovered as WPL trajectories. Besides higher apprenticeships, this would traditionally not involve a higher education (HE) award whereas WBL would. Australians and Canadians avoid this cross-conceptualisation by referring to all of these concepts as work integrated learning. Nottingham (2017) argues that workforce development and apprenticeships (I would suggest higher apprenticeships are being described here) are newer variations of WBL. WRL would involve the preparation for or learning about work (Allan, 2015). This will also not necessitate a $\mathrm{HE}$ award. WBL is therefore unique in that it is a programme of learning validated by a higher education institution. In conjunction to the $\mathrm{HE}$ award, WBL aims to develop professional knowledge, professional skills and professional attitudes (Garnett, 2016; Toledano-O'Farrill, 2017). The changing nature of work and the modern enterprise is calling on more professions to be ready to change and work in multi-disciplined and interdisciplinary contexts, considering practice in new ways producing new forms of knowledge (Mardini, 2013).

\section{The research context}

GSM London is a business management (BM) college with a widening participation ethos. Students have an average age (in 2017) of 30 making it predominantly focussed on adult education. The GSM London student body is 90 per cent black Asian minority ethnic with 16 per cent from participation of local areas (POLAR) 1 and 2 post codes, i.e., areas of low educational attainment and aspiration (www.gsmlondon.ac.uk/about-us/ vision-and-mission).

At GSM London, Level 5 (second year) UG WBL projects are explicitly linked to the development of partnerships between students, GSM London and businesses in order to provide work-like experiences. The Level 5 UG project modules (30 credits each) are called project placement design implementation (PPDI) and Evaluation and Reflection (EVRE). The former provides the WBL project experience in groups and the latter guide's reflection upon that experience. The modules are taught across a ten-week period across nine disciplines such as human resource management (HRM), BM, oil and gas management, events and entertainment management, travel and tourism management, BM with creative industries, BM with e-commerce, enterprise and small business development and marketing. A 2 -h PPDI lecture early in the week is followed by 3 -h project groups, subject and project specific. These are followed mid-week by 2 -h EVRE lectures followed by 3 -h workshop groups, subject specific. The researcher facilitated a project group of HRM students working on a project for a European wide charity. The project brief was to create an upgraded professional code of conduct policies. It was in this group, using action research, that a leadership intervention was made. All projects are conducted in groups. Each group nominates a project leader. It has been the researchers observation that the success of the project and the learning gained from it is often dependent upon the successful leadership of the project leader. A good project leader would usually be confident, communicate well, monitor the pace of the project, manage allocated tasks and manage conflict to maintain positive group dynamics. It has not been a custom for project tutors to provide any 
formalised support to the nominated group leaders. Whether such an intervention of leadership would impact upon the groups and nominated leaders is the focus of this paper.

Similar to Costley and Abukari (2015), students complete a learning contract (LC) (30 per cent of the final mark) signed by their project tutor in Week 4 to endorse the WBL project as an appropriate research and development project. A final project report (PR) (70 per cent of the mark) is also produced. Projects as an independent assignment are a key element of WBL (Lemanski and Overton, 2016) and are seen as initial professional preparation (Allan, 2015). It is for this reason that WBL is seen by stakeholders as a way to support the professional development of learners, for whom the learning is focused on the context of their workplace (Lemanski and Overton, 2016). Lifelong learning accentuates the ever-changing nature of the workplace and through reflective practice, i.e., the EVRE module, fostering one's capacity to learn, review and adapt and so foster self-directed learning (Newman and Farren, 2018). It is for this reason that reflection has a vital role within WBL, delivering HE responses to flexible and rapidly changing labour markets (Garnett, 2016).

\section{Reflection and leadership}

Moon (1999) defines reflection "as a process of learning and the representation of that learning". This means that reflection is not just about the acquisition of knowledge but also, if not more importantly, it is also about the appropriate application or manifestation of that knowledge as evidence of that learning. Reflection is a complicated mental processing of ill-material, a term created by Moon (1999) referring to uncertain material or unpredictable circumstances such as what surfaces during PPDI projects. These circumstances are common place among students on WBL projects and reflective practice is the best method to learn how to work with this ill-material, to change and adapt (Gerhardt, 2013). This could very pertinent for those nominated as project leaders. WBL projects highlight that students not only need to demonstrate learning in order to be appointed to a job, but also how to improve their knowledge and skills on an ongoing basis, adapting to the evolving demands of their work (Garnett, 2016). Toledano-O'Farrill (2017) adds that reflection, integral to professional learning, allows the student to transform experience into learning.

Reflection is a deliberate mental process/tool/skill which leads to an outcome, the practice of professionals whereby they think in action (or after action) and theorise about that practice while or after they do it (Jasper, 2006). The outcome of such practice is to improve the professional and their professional practice (Schon cited in Graham et al., 2005). Such competent people are people who are able to apply their knowledge under changing conditions (Knowles, 1980). It is for this reason that many WBL projects include evidence such as reflective skills development portfolios (Lemanski and Overton, 2016). This produces Mode 2 knowledge which is highly contextual, practically focussed and often unsystematic in contrast to Mode 1 knowledge categorised in subject disciplines which is linear, formal, cumulative and generalisable (Garnett, 2016). However, most of the students have never really come across reflection theory or practice. The EVRE workshop tutors, therefore, facilitate the practice and experience of this skill.

An intervention of leadership among nominated leaders may therefore predominantly be about facilitating reflection rather than any explicit input on leadership or specific leadership development strategies. For example, McChrystal (2015) illustrates this well in his discussion and comparison between airline incidents, United 173 and the US Airways 1549. He explains the difference between "command and control" and "adapt and collaborate". WBL similarly is more about how to adapt theory in changing contexts and reflection is pivotal to enable that adaption and collaboration to take place, not just following rules regardless of context. The intervention, to facilitate reflection among

Impact of a leadership intervention 
JWAM

11,1

nominated group leaders, was more the focus than on commentary on leadership per se. The intervention was therefore more about facilitating reflection on group leadership than supporting leadership development, although this may be a bi-product as a result.

\section{Project context}

The PPDI project module aims to provide a WBL experience so that students can submit a LC and PR. Students are given a LC template which they complete individually and personally containing the aim of the project, module learning outcomes, the justification of the project in terms of personal skills development relevance and the methods to be used in the project accompanied by a Gantt chart. The PR has specified sections they need to report on such as the context of the project, theories and models applied, skills developed, analysing the project phases, actions they did or did not take and what learning they gained as a result of the project. To help start them on building a portfolio of evidence, we provide them with templates to complete for a weekly learning $\log$, a project $\log$ and a critical incident log. Both submissions aim to fulfil the following learning outcomes:

(1) build a portfolio of evidence using a range of methodologies and activities such as project, weekly learning and critical incident logs;

(2) identify and article the development of work-related skills mapped to evidence drawn from the project;

(3) demonstrate knowledge and understanding of the background and context relative to the chosen project; and

(4) evaluate the effectiveness of preparation and planning undertaken prior to the project implementation.

Because this was an action research intervention, nominated group leaders were not aware of the "planned intervention" in order to avoid response bias. The design of a standard feedback process from the participants was therefore not pursued for that reason, relying solely on whether the intervention would be naturally mentioned in the common assessment work. The project phase happens between Weeks 4 and 8. The impact of an intervention of leadership, therefore, between Weeks 3 and 7 should be visible in the content of the LC and $\mathrm{PR}$, especially in the project and weekly learning logs (if the intervention altered the research context). The intervention varied each week and was dependent upon what issues the group leaders discussed and which theories covered in the module I could help facilitate in practice. For example, one such intervention was to encourage the leaders to see themselves as another group (a leaders group) and so encourage and support one another in their common task as a leader.

\section{Methodology}

There are different WBL methodologies such as WBL with various degrees of negotiation, critical reflective practice, action research and action inquiry (Wall et al., 2017). The context of this study was a project tutor adopting the role of a practitioner researcher by facilitating a WBL project as part of GSM London's Level 5 UG project PPDI module. A project group of $20 \mathrm{HRM}$ students were divided into four groups in Week 2 of the ten-week project cycle. Each group nominated a leader. The project tutor, using one action research cycle, introduced a leadership intervention in Weeks 3-8. During each of those weeks he met with the nominated leaders to support and enable them in their role as nominated group leaders by primarily facilitating reflection on their experiences including work-based application and testing knowledge (Garnett et al., 2016). The impact of this intervention will be 
ascertained by a content analysis of their PRs identifying leadership reflections, monitoring and evaluations. A process of planning, acting, observing/reflecting, evaluating and validating will be followed (Molineux, 2018).

Similar to cross-conceptualisation in WBL, action research is also associated with other concepts such as action inquiry or collaborative, participative, emancipatory inquiry but fundamentally it is a "research strategy which sets out to change the situation being researched" (Scott and Morrison, 2007), and in this case to avoid response bias, the motive behind the action was done without the knowledge of participants. Action research incorporates cycles of action, reflection, learning and planning (Molineux, 2018). The researchers intervention is the action, the content analysis is the reflection and the implications for future WBL projects are the learning and planning. Content analysis, as an obstructive technique, allows researchers to analyse relatively unstructured data for meanings such as WBL portfolios (Merriam and Tisdell, 2016).

\section{The intervention action}

In Week 2, the students decided to allocate themselves into four groups. Project leaders were nominated and teams started their group work with two key tasks: allocate tasks for the project, watch high-performing teams on Lynda.com and present as a group the following week how they will implement strategies to be a high-performing team. All teams presented in Week 3. After the presentations, the researcher called all group leaders aside separately to inform them that the researcher would be meeting with them as group leaders from now on each week until Week 7 in order to support them in their specific task of leadership, i.e., the intervention. It was not about providing input on leadership but rather facilitating reflection on leadership. The key intervention each week is indicated below:

- Week 3 - to instil confidence and trust and that the researcher will be here to listen and support. Leaders reflected on the first group presentations.

- Week 4 - the researcher met with each leader continuing Week 3's theme but also now monitoring how the leaders were driving the pace of the project to keep tasks being fulfilled. Each leader had to give a progress report. At this stage, some leadership issues were beginning to surface in one particular group. The group reflected upon solutions.

- Week 5 - the researcher met with each leader individually to repeat Week 3's theme. The researcher facilitated reflection on individual experiences.

- Week 6 - the researcher recapped and clarified the project task and continued the theme of instilling confidence. The researcher facilitated reflection upon knowledge gained such as the Thomas-Kilmann conflict indicator (Kilmann and Thomas, 1977), and the DISC management profile (Sugerman et al., 2011) which was complete by all. There was also a change of leadership in one group, with one leader "stepping down" to allow another to take the leadership of the project. The researcher spent time on e-mail that week with this new leader discussing ways to restore confidence and focus in the new leaders struggling team.

- Week 7 - the researcher encouraged the group to be a group of leaders within the other groups and support one another in their task as leaders. The researcher also helped them plan their stakeholder presentations.

- Week 8 - the researcher debriefed all the leaders discussing the experiences and what they had gained as leaders.
Impact of a leadership intervention 
JWAM

11,1

\section{Reflection on content analysis}

Leaders will be referred to as Group Leader 1-4 (GL1, etc.). The group that had a change in leadership will be referred to as GL4a to indicate the initial leader and GL4b to indicate the new leader. The total group leader samples, therefore, are GL1, GL2, GL3, GL4a and GL4b. A content analysis of the LC (and the PR will be displayed in a table. The content analysis will identify any mention or intention of leadership for each GL in their LC and PR. The latter is the particular key in identifying the intervention. Content in the LC and PR will also be associated specifically with the intervention for each week, i.e., week 3 , week 4 , week 5 , week 6 ,week 7 and week 8 .

The content analysis results can be seen in Table I followed by a reflection on learning and planning.

\section{Learning and planning}

The content analysis of the five group leaders in Table I demonstrates the vast experience and learning that manifested in a WBL project module. It is important to emphasise that the content analysis was not an analysis of the quality of the submissions by the five group leaders or the accuracy of their experiences. In this regard, it is clear that there are significant differences.

As an indication of intention, only four of the group leaders mentioned their intention to develop leadership skills in their LCs (GLs 1, 2, 3, 4a). Two articulated confidence in their ability as a leader (GLs 2, 3). Only three of the leaders specifically mentioned the leadership intervention in their PR and portfolio of evidence (GLs 1, 2, 3). Two mentioned advice from the researcher but whether this is a part of the formal intervention is not clear (GLs 4a, 4b). Although not documented in detail in the assessed work, the advice was about applying the theory gained from the module to their group leadership experiences. For example, advising both leaders to take into account the groups test results for the DISC management profile and Thomas-Kilmann conflict instrument in their communication with the group (GL4b). Feedback as such was an important action mentioned by some.

Two group leaders mentioned the establishment of a group for leaders to offer each other peer support (GLs 1,2). Confidence in leadership ability was mentioned by four group leaders as an indication of the importance of this factor (GLs 1, 2, 3, 4a). The intervention could not prevent the breakdown of leadership in one group but may have helped to reduce the negative impact (GLs 4a, 4b).

The learning gained as expressed in the assessment work about the impact of the leadership intervention is inconclusive. Most felt it important enough to be mentioned as they reflected upon the impact of the experience. Other aspects such as peer leadership support even less so. Whether more may be mentioned if there was leadership input and not just facilitation is worth considering for future planning. To understand and analyse better the impact of such a leadership intervention on their reflection by analysing their corresponding EVRE submissions was considered. However, one script was confirmed as an academic misconduct of collusion and so ruled out this possibility. There is, however, enough articulation of the intervention in their PPDI submissions to consider implementing this leadership intervention across more projects to facilitate leadership theory into practice and instil confidence. However, further formal leadership input to enhance the facilitation and so increase the impact of such an intervention will be implemented for such future interventions. In a WBL context, it is significant enough to mention that not all theory from the module was considered by the leaders in their experience of leadership and the theory that was considered needed reflective facilitation by a tutor (an intervention) to enhance implementation more effectively. 
Learning contract

GL1 Overall through this portfolio, there are various skills involving, leaderships skills $[\ldots]$ that are being developed and/or are present skills that I feel need to be improved [in justification]
GL2 Demonstrate leadership skill and motivation of team members to enhance high performance in achieving task [added LO] [...] my leadership skill will enable me [o forge the group [...] to demonstrate my leadership skill [...] [in method]

GL3 [...] help me to accommodate everybody's idea on this project as a leader [in justification] $[\ldots]$ involvement in the project will
Project report

Throughout my PPDI experience I have established my ability to be more than just a team member, but the ability to be a leader [in executive summary]

As the agreed leader $[\ldots]$ volunteering to be the leader $[\ldots]$ [in actions taken] first project as project leader [in the stakeholder analysis grid] leader meetings [in the stakeholder analysis grid][...] developing leadership skills [...][in learning gained] [...] although the appointed leader, I have also developed my teamwork building skills [in learning gained] The most important part that has haunted me throughout this module, was if I could be a successful leader [...] [in learning gained] Team Leader meeting with [researcher] [...] got necessary information, voiced stress and learnt we have a very supportive tutor [in project log] - Week 3 Individual Team Leader meeting with [researcher] [...] continue to utilise great support from tutor [in project log] Week 5

[Researcher] advised for all leaders to bring brief progress report to next class [...] continue to utilise great support from tutor [in project log] - Week 6

Handed in brief progress report to [researcher] [in project log] - Week 6

Last Team leader meeting [...] was encouraged to have each leader support one another as we are our own group within a group [...] continue to advise other group leaders on any struggles they may endure through the project [in project log] - week 7

GL2 created group leader group chat [in project log] - Week 7 Group leader debrief with [researcher] [in project log] - Week 8 Be less accommodating if leader [in project log] - Week 8 Volunteered to be a group leader [in weekly learning log] Week 2

Individual Group leader meetings with Tutor [...] individual meeting with tutor was assuring and have learnt we have a great tutor support system [in weekly learning log] - Week 5 I was making sure the group was working effectively and keeping members up to date with outcomes of the meetings with other group leaders and the tutor [in actions taken] Meetings of group leaders with tutor [in weekly learning log] Week 3

Formed a group leader what's app page to support each other [in weekly learning $\log$ ] - Week 4

Learning conflict resolution. Group leaders meeting.

[in weekly learning $\log$ ] - Week 6

Group leaders meeting with the tutor [in weekly learning $\log$ ] Week 7

All group leaders were dissolved [in weekly learning log] Week 8

The group leader gave us feedback from meeting they had with the tutor [in meeting minutes]

This is the first group leader's meeting with our tutor, 1 learnt the importance of feedback in the activity
Impact of a leadership intervention

Table I. Content analysis results 
Learning contract

allow me to demonstrate my leadership skill as 1 had been chosen as the team leader [in justification] I intend practising a leadership style that ensures every member is given the opportunity to express their opinion because mutual respect elicit trust and togetherness in a group [in justification] [...] to enhance my communication skill as a leader [in justification]

GL4a [...] to receive feedback from peers and tutors so I could see where I could better and improve my leadership skills [in justification] $[\ldots]$ help build the team as well as my own confidence as the leader. [in justification]

GL4b [no mention of leadership]

\section{Project report}

How constructive feedback can help me adjust areas of weakness and avoid barriers that could affect my job, 1 understands how to use my strength to actualise my vision. [in weekly learning $\log$ ] - Week 4

As the group leader, I informed the group about the tutor feedback on team performance at the group leader meeting with our tutor, the feedback was well received, the group decided to work with the information especially our area of improvement. [in weekly learning log] - Week 5

The Group leaders met with our tutor again to find out what is happening in the group and how we are getting on, I was happy to inform him that my group was doing fine though we had our moments, frictions, panic attacks and arguments but we only disagree to agree. [in weekly learning $\log$ ] - Week 5 [...] advice from my project leader whom gave me advice due to my concerns of leading a group [in actions taken]

[...] the team leader stepping down from the position and the group requesting I take over [in models and theories]

In week five the group reviewed leadership and decided to change [in project phases]

$[\ldots]$ frustrated and regretting not taken up the leadership role [in actions not taken]

I emailed the project leader requesting for advice in which I was asked to complete a task on my perception on the group which involved using the different models and theories learned in class. [in actions taken]

As part of forming a group, we must have a nominated group leader. Everyone did not want to be a leader, and some even suggested I should be a leader. Although it is a role I have naturally taken up, this time round I felt I should not because of I do not know the group members too well. As a result, one member put herself up. [in weekly learning $\log$ ] - Week 2

My Group came to the decision that is time for a new leader as original leader was not performing. All members decided I best suited the role. I am not sure if this is the best decision as I feel it was more of an easy way out. [in weekly learning $\log$ ] week 5

Meeting with the lecturer and discuss issues. [in project log]Week 5

Table I.
Nominated to be the leader of the group. [in project log] Week 5

\section{Conclusion}

Strong emotional energy (Wall et al, 2017) exercised in a leadership facilitation intervention can affect confidence and self-belief in adult learners through their reflective practice which can impact their motivation and desire to become agents of change and to create learning opportunities in a culture of openness with others (Newman and Farren, 2018). This motivation was evident in most of the group leaders. The facilitation of motivation through 
a leadership intervention will invariably lead to improved productivity, i.e., successful WBL project experiences, which impacts upon personal and professional confidence and credibility (Costley and Abukari, 2015). As the Researcher, I have observed an increase of psychological (Wall et al., 2017) and intellectual capital (Garnett et al., 2016) among the group leaders due to the intentional leadership intervention to facilitate the application of leadership theory upon practice and instil confidence in the application of these actions. It appears, at least in my case, that too many assumptions are made about students applying appropriate theory in practice in WBL contexts.

\section{References}

Allan, D. (2015), "Conceptualising work learning: exploring the educational discourse on work-based, work-related, and workplace learning", E-Journal International, Vol. 5 No. 1, pp. 1-20.

Costley, C. and Abukari, A. (2015), "The impact of work-based research projects at postgraduate level", Journal of Work-Applied Management, Vol. 7 No. 1, pp. 3-14.

Garnett, J. (2016), "Work-based learning: a critical challenge to the subject discipline structures and practices of higher education", Journal of Higher Education, Skills and Work-Based Learning, Vol. 6 No. 3, pp. 305-314.

Garnett, J., Abraham, S. and Abraham, P. (2016), "Using work-based and work-applied learning to enhance the intellectual capital of organisations", Journal of Work-Applied Management, Vol. 8 No. 1, pp. 56-64.

Gerhardt, T. (2013), "The use, effect and further development of the tool of reflection in adult theological education in relation to the formation of Anglican curates", Journal of Adult Theological Education, Vol. 10 No. 2, pp. 132-146.

Graham, E., Walton, H. and Ward, F. (2005), Theological Reflection: Methods, SCM Press, London.

Helyer, R. (Ed.) (2016), Facilitating Work-Based Learning, Palgrave, London.

Jasper, M. (2006), Professional Development, Reflection and Decision-Making, Blackwell Publishing, Oxford

Kilmann, H.R. and Thomas, W.K. (1977), "Developing a forced-choice measure of conflict-handling behavior: the 'mode' instrument", Educational and Psychological Measurement, Vol. 37 No. 2, pp. 309-325.

Knowles, M.S. (1980), The Modern Practice of Adult Education: From Pedagogy to Andragogy, Association Press, Chicago, IL.

Lemanski, T. and Overton, T. (2016), "The development of mapping tool for work-based learning activities", Journal of Higher Education, Skills and Work-Based Learning, Vol. 6 No. 3, pp. 277-287.

McChrystal, S. (2015), Team of Teams: New Rules of Engagement for a Complex World, Penguin, New York, NY.

Mardini, J. (2013), "Creating and evaluating an online and work-based instructional model", Journal of Higher Education, Skills and Work-Based Learning, Vol. 3 No. 1, pp. 30-50.

Merriam, S.B. and Tisdell, E.J. (2016), Qualitative Research: A Guide to Design and Implementation, 4th ed., Jossey-Bass, San Francisco, CA.

Molineux, J. (2018), "Using action research for change in organizations: processes, reflections and outcomes", Journal of Work-Applied Management, Vol. 10 No. 1, pp. 19-34.

Moon, J.A. (1999), Reflection in Learning and Professional Development, RoutledgeFalmer, London.

Newman, E. and Farren, M. (2018), "Transforming self-driven learning using action research", Journal of Work-Applied Management, Vol. 10 No. 1, pp. 4-18.

Nottingham, P.M. (2017), "Re-evaluating work-based learning pedagogy", Journal of Higher Education, Skills and Work-Based Learning, Vol. 7 No. 2, pp. 129-140.

Scott, D. and Morrison, M. (2007), Key Ideas in Educational Research, Continuum, London. 
JWAM

11,1

Sugerman, J., Scullard, M. and Wilhelm, E. (2011), The 8 Dimensions of Leadership: DiSCC Strategies for Becoming a Better Leader, Berrett-Koehler Publishers, Oakland, CA.

Toledano-O'Farrill, R. (2017), "Professional application projects: work-based learning in the curriculum", Journal of Higher Education, Skills and Work-Based Learning, Vol. 7 No. 1, pp. 21-34.

Wall, T., Russell, J. and Moore, N. (2017), "Positive emotion in workplace impact: the case of a workbased learning project utilising appreciative inquiry", Journal of Work-Applied Management, Vol. 9 No. 2, pp. 129-146.

\section{Further reading}

Greenwich School of Management (2018), "About us", Greenwich School of Management, London, available at: www.gsmlondon.ac.uk/our-history (accessed 7 January 2019).

Helyer, R. (2015), The Work-Based Learning Student Handbook, 2nd ed., Palgrave, London.

\section{Corresponding author}

Trevor Gerhardt can be contacted at: dr.trevor.gerhardt@gmail.com

For instructions on how to order reprints of this article, please visit our website: 